\title{
As principais dificuldades de imigrantes russófonos na escrita em português brasileiro: análise de redações elaboradas durante a preparação para o Celpe-Bras
}

\section{Anna Smirnova Henriques* \\ Resumo}

Mais da metade dos migrantes russófonos chega ao Brasil sem ter nenhuma noção sobre a língua portuguesa e aprende português de maneira autônoma, sem contato com a instrução formal. No entanto, em 2018, o exame de proficiência em português brasileiro Celpe-Bras se tornou obrigatório para a naturalização, e a falta de instrução formal se tornou um empecilho nesse caminho. Neste trabalho, são descritas as principais dificuldades na escrita em português de migrantes russófonos, fluentes em português falado, identificadas nas redações elaboradas durante um curso preparatório para o Celpe-Bras. Elas incluem as dificuldades de ortografia, uso de acentuação, uso de artigos, concordância de gênero, uso de verbos (conjugação, tempos verbais, modo subjuntivo) e ordem de palavras nas frases. Apesar dessas dificuldades, os migrantes russófonos estruturam bem o texto e têm facilidade para adquirir um vasto vocabulário. Ao estudarmos a aquisição do português por migrantes russófonos no Brasil, trazemos duas línguas do grupo linguístico indo-europeu pouco confrontadas nos estudos da área de aquisição de L2: o russo, uma língua eslava, e o português, uma língua românica. Para estimular o estudo das dificuldades de migrantes na aprendizagem de português brasileiro, a criação de um corpus de aprendizes de português brasileiro como língua estrangeira se configura em iniciativa de grande valor.

Palavras-chave: Português como língua estrangeira. Russófonos. Celpe-Bras. Migração. Escrita.

\footnotetext{
* Pontifícia Universidade Católica de São Paulo (PUC-SP). Pós-Doutoranda no Laboratório Integrado de Análise Acústica e Cognição (LIAAC), Programa de Estudos Pós-Graduados em Linguística Aplicada e Estudos da Linguagem (LAEL). Orcid: 0000-0003-3011-372X.
} 


\title{
The main difficulties of Russophone immigrants in writing in Brazilian Portuguese: analysis of essays produced during a preparatory course for the Celpe-Bras exam
}

\begin{abstract}
More than half of the Russophone migrants arrive in Brazil without knowing Portuguese and acquire the Portuguese language on their own, without previous formal instruction experience. However, in 2018, Celpe-Bras, a Brazilian Portuguese proficiency exam, became mandatory for naturalization purposes, and the lack of formal education became an obstacle along this path. This work describes the main writing difficulties faced by Russophone migrants, as identified in the essays produced during a preparatory course for the Celpe-Bras exam. They include spelling difficulties, use of graphic accentuation, use of articles, gender agreement, use of verbs (conjugation, verb tenses, subjunctive mode) and word order in sentences. Despite these difficulties, Russophone migrants structure the text well and easily acquire an extensive vocabulary. Considering the acquisition of Brazilian Portuguese by Russophone migrants, our focus is on languages of the Indo-European linguistic group which have been scarcely considered in relation to each other in the field of L2 Language Acquisition: Russian, a slave language and Portuguese, a romance language. To stimulate the study of the migrants` difficulties in learning Brazilian Portuguese, the building of a Brazilian Portuguese as a Foreign Language Learner Corpus would be of great value.
\end{abstract}

Keywords: Portuguese as a foreign language. Russophones. Celpe-Bras. Migration. Writing.

Recebido em: 18/03/2021 // Aceito em: 09/04/2021. 


\section{Introdução}

A dissolução da União Soviética em 1991 provocou uma grande onda de emigração de falantes de russo para os países onde as condições económicas eram melhores; em primeiro lugar, Alemanha, EUA, Israel e França (ZHOU; KOLODA, 2019). A análise de fluxos de migração de cidadãos da Rússia mostra que, a partir de 2001, os países da América Latina também se tornaram um destino migratório importante (VOROBYEVA; ALESHKOVSKI; GREBENYUK, 2018). No entanto, o termo "russófono" não se refere somente aos cidadãos da Rússia, mas também aos falantes de russo dos estados pós-soviéticos, inclusive os que não se consideram russos etnicamente (PANARIN, 1999). Nos países ex-soviéticos, como Ucrânia, Cazaquistão e Belarus, mais de $60 \%$ da população falam russo (ZHOU; KOLODA, 2019). A recente análise dos dados do Banco Interativo do Observatório das Migrações em São Paulo mostra que, nos últimos 20 anos, o registro administrativo na Polícia Federal brasileira foi solicitado por 7.031 imigrantes da Rússia, 4.261 imigrantes da Ucrânia, 548 do Cazaquistão e 265 da Belarus (SMIRNOVA HENRIQUES; RUSEISHVILI, 2019; SISMIGRA, Banco Interativo, 2020). Em torno de 28\% dos imigrantes da Rússia se registraram no estado de São Paulo.

$\mathrm{O}$ nosso grupo recentemente aplicou um questionário a 97 migrantes russófonos que moravam/moraram em diferentes lugares do Brasil e demonstrou que 58\% deles aprenderam português sozinhos, depois de se mudarem para o Brasil, sem contato com a instrução formal (SMIRNOVA HENRIQUES $e t$ al., 2019). Na Rússia, as oportunidades de aprender português brasileiro para as pessoas que têm intenção de emigrar são 
As principais dificuldades de imigrantes russófonos na escrita em português brasileiro: análise de redações elaboradas durante a preparação para o Celpe-Bras

escassas, restritas a dois centros culturais em Moscou e São Petersburgo e a algumas escolas particulares (AREFIEV, 2019). Como no Brasil as oportunidades de receber uma instrução formal em português brasileiro como língua estrangeira também são limitadas (ACNUR, 2019; ADAM; FERNANDES MASSUCI; FURTOSO, 2009; AMADO, 2013; FARNEDA, 2019), somente $7 \%$ dos imigrantes russófonos ingressaram numa escola de idiomas no Brasil depois da sua chegada (SMIRNOVA HENRIQUES et al., 2019). Entre 40 russófonos que deram entrevistas dentro do projeto de construção do banco de dados de russófonos de São Paulo, somente dois entrevistados mencionaram que fizeram um curso de português como língua estrangeira em alguma instituição brasileira (SMIRNOVA HENRIQUES et al., 2020). Um desses migrantes fez o curso para estrangeiros na FFLCH-USP (Faculdade de Filosofia, Letras e Ciências Humanas da Universidade de São Paulo) e outro na FAAP (Fundação Armando Álvares Penteado). Mais uma pessoa, com o objetivo de melhorar a sua escrita em português, ingressou no Cieja (Centro Integrado de Educação de Jovens e Adultos) e fez um semestre de ensino fundamental.

Como a maioria dos imigrantes russófonos adquire português no Brasil sem ter acesso à instrução formal, eles enfrentam dificuldades significativas em se preparar para o exame de Celpe-Bras, cujo certificado de proficiência (caso não haja um meio alternativo de comprovação de proficiência, como um diploma de uma instituição de ensino superior brasileira) é exigido para a naturalização desde 2018 (BRASIL, 2018; SMIRNOVA HENRIQUES; RUSEISHVILI, 2019). Além de uma prova oral de 20 minutos, o Celpe-Bras inclui quatro redações que precisam ser escritas em três horas com base em 
um áudio, um vídeo e dois artigos de jornal/revista, usando o estilo formal (PÉRET DELL'ISOLA, 2014). Mesmo os imigrantes russófonos que são fluentes em português falado não conseguem boas notas na redação sem uma preparação específica (SMIRNOVA HENRIQUES; RUSEISHVILI, 2019). Nesse grupo, destacam-se as mulheres com filhos pequenos, esposas de homens brasileiros, que desejam ter a cidadania brasileira para facilitar a vida familiar, mas não têm a disponibilidade de tempo de se aprofundar no estudo do português formal. Nesse contexto, o Celpe-Bras é considerado por alguns autores como um instrumento linguístico gatekeeper no caminho da aquisição de cidadania por migrantes (ANUNCIAÇÃO; CAMARGO, 2019).

O objetivo deste trabalho é descrever as principais dificuldades na escrita em português de imigrantes russófonos, fluentes em português falado, identificadas nas redações elaboradas durante um curso preparatório para o Celpe-Bras, ministrado pela autora em 2018 durante três meses na modalidade on-line. As redações, analisadas no trabalho, estão disponíveis em formato digital, o que possibilita a futura inclusão desses dados em um corpus de aprendizes de português brasileiro como língua estrangeira.

\section{Dificuldades de russófonos na aprendizagem de português: revisão de literatura}

No contexto brasileiro, as dificuldades de russófonos na aprendizagem de português têm sido estudadas exclusivamente do ponto de vista da pronúncia. Assim como os falantes de muitas outras línguas maternas, os imigrantes russófonos têm 
As principais dificuldades de imigrantes russófonos na escrita em português brasileiro: análise de redações elaboradas durante a preparação para o Celpe-Bras

dificuldades na discriminação de vogais médias $/ \varepsilon /$ - /e/ e /o/ - /o/, em produzir a nasalização correta e controlar o desvozeamento de consoantes (VITORIANO DE ALMEIDA et al., 2018; SMIRNOVA HENRIQUES et al., 2019; 2020; SMIRNOVA HENRIQUES; BARROS; MADUREIRA, 2020). No entanto, há estudos mais abrangentes sobre as dificuldades de russófonos na aprendizagem de português desenvolvidos na própria Rússia, no ambiente acadêmico, e em Portugal.

Em relação ao estudo de português no ambiente acadêmico na Rússia, Arefiev (2019) destaca que o português não é ensinado em nenhuma das escolas da Rússia, mas os cursos de português, principalmente na sua modalidade continental, existem em nove instituições de ensino superior; no ano acadêmico 2017/2018, o português era estudado por 459 estudantes. A maioria das instituições de ensino fica em Moscou (Universidade de Relações Internacionais de Moscou, Universidade Estatal de Linguística de Moscou, Universidade Estatal de Moscou, Universidade Militar do Ministério de Defesa, Academia Diplomática do Ministério de Relações Exteriores da Federação Russa, Universidade Estatal Russa de Ciências Humanas), mas também há três em outras cidades (universidades estatais de São Petersburgo, Tomsk e Voronej). Baseado nos dados dos censos aplicados na Rússia em 2002 e 2010, Arefiev (2019) avalia o número atual de russos proficientes em português, residentes na Rússia, em torno de 15 mil.

Embora ainda não haja uma análise sistêmica de diferenças estruturais entre russo e português, Petrova, professora da Universidade de Relações Internacionais de Moscou (MGIMO), publicou uma série de trabalhos sobre o assunto. No Departamento de Português da MGIMO, há nove professores, todos nativos 
de russo, e em torno de cem estudantes (PETROVA, 2011). Conforme a descrição de Petrova, o curso prioriza a variante europeia de português porque muitos fenômenos gramaticais que nela existem não existem na variante brasileira. Os alunos do curso têm 10 horas de aulas de português por semana durante quatro anos de licenciatura e podem trabalhar como intérpretes e tradutores. Em 2011, baseada na sua experiência de ensino de português como língua estrangeira na MGIMO, Petrova levantou uma lista de fenômenos fonéticos, gramaticais e lexicais de português que não têm correspondência na língua materna de falantes nativos de russo. Segundo a autora, as principais dificuldades dos alunos incluem: 1) uso de artigos (não existentes em russo); 2) concordância de tempos verbais (em russo, antecedência em relação ao passado não é explicitada, não há pretérito mais-que-perfeito nem o futuro do pretérito); 3) sistema de pronomes pessoais (uso de pronomes de terceira pessoa para conversar com alguém que em russo trataríamos com pronomes de segunda pessoa; omissão de pronomes pessoais; uso de pronomes pessoais na posição anafórica); 4) uso de verbos ser/estar (em russo esses dois verbos se traduzem com um mesmo verbo que, além de tudo, é omitido no presente); 5) uso de pronomes reflexivos (em russo eles não variam em pessoa e número); 6) a concordância dos pronomes possessivos em terceira pessoa (em russo eles concordam em pessoa e em gênero com o possuidor); 7) ordem de determinante e determinado (em russo a ordem estilisticamente neutra é determinante seguido por determinado); 8) uso do modo subjuntivo (em russo, os verbos no modo subjuntivo não têm indicadores morfológicos de tempo).

Em 2016, Petrova publicou um trabalho no qual analisa os erros típicos na tradução de russo para português dos estudantes 
As principais dificuldades de imigrantes russófonos na escrita em português brasileiro: análise de redações elaboradas durante a preparação para o Celpe-Bras

falantes de russo do quarto ano de bacharelado em português como língua estrangeira da MGIMO. O nível de proficiência desses estudantes é considerado como $\mathrm{C} 1$ (avançado). A autora destaca o uso incorreto de artigos definidos e de pronomes pessoais, possessivos e indicativos, as dificuldades no uso de tempos verbais não existentes em russo, as dificuldades no uso dos verbos ter/haver e ser/estar, a interferência da língua materna na ordem de palavras e o uso de sequências excessivamente longas de substantivos (possível em russo) conectados através de múltiplos usos da preposição "de" ("dedeísmo"). No seu último trabalho, em 2019, Petrova focaliza as diferenças lexicais entre russo e português em relação aos conceitos de tempo e espaço.

Outras pesquisas sobre o assunto foram desenvolvidas em Portugal. Silva (2009) estudou como os imigrantes russófonos que utilizam português no contexto laboral usam as oposições aspectuais dos verbos e comparou os resultados entre os que tiveram alguma instrução formal em português e os que nunca tiveram contato com a explicação de regras linguísticas dessa língua. O tempo de residência em Portugal da maioria desses migrantes era de 1 a 10 anos. A autora aplicou um questionário que continha enunciados de frases simples e complexas, elaboradas com base em algumas configurações do aspecto verbal em português, considerando também a categoria verbal de tempo. Os resultados mostraram que a aprendizagem formal não é tão relevante para o reconhecimento de valores aspectuais do português quanto a influência do contexto de imersão em que o falante está inserido. Por exemplo, ambos os tipos de informantes reconheciam valores aspectuais como o progressivo e o habitual em várias situações e tiveram dificuldades em reconhecer o valor imperfectivo de formas de pretérito perfeito 
composto. Além disso, independentemente da aprendizagem formal, os imigrantes demonstraram dificuldades em diferenciar noções aspectuais pela morfologia da forma verbal e se guiavam pelos advérbios temporais. A autora também observou que as competências na oralidade desses migrantes superam as competências na escrita.

Em seguida, Baldé (2011) estudou a aquisição do artigo em português L2 por falantes de L1 russo que pertencem à primeira geração de imigrantes e chegaram a Portugal sem nenhum contato prévio com a língua portuguesa, com o tempo médio de residência de 6,7 anos e a instrução formal em português escassa. A autora adaptou ao português o teste de ocorrência de artigos em inglês como L2 (IONIN; KO; WEXLER, 2004) e observou que os migrantes russófonos têm mais dificuldades no uso do artigo indefinido do que no do definido. Segundo as suas conclusões, a maior facilidade de aquisição de artigo definido pode ser relacionada ao fato de que ele ocorre mais frequentemente no input e se usa em um leque mais alargado de contextos.

Finalmente, Stsepaniuk (2014), baseando-se nas dificuldades de alunos russófonos descritas por Petrova (2011; 2016; 2019), elaborou uma proposta de materiais didáticos bilíngues russo-português adaptados para o ensino de português continental. Travina (2019) relatou a sua experiência de ensino de português continental a adolescentes russos em um campo de férias na Rússia durante 21 dias e também descreveu algumas dificuldades dos aprendizes na escrita. Entre elas, constavam o uso de pronomes possessivos, a concordância de gênero, o uso de artigos, a conjugação de verbos, o uso de preposições, a regência do verbo "gostar", o uso de expressões com "ter" e "ser" e o uso de acentos gráficos, ausentes em russo. 
As principais dificuldades de imigrantes russófonos na escrita em português brasileiro: análise de redações elaboradas durante a preparação para o Celpe-Bras

A partir do conteúdo acima descrito, podemos concluir que as dificuldades de russófonos na aprendizagem de português são descritas mais detalhadamente no contexto de ambiente acadêmico das universidades russas, quando se trata de estudantes de tradução. No entanto, as dificuldades de estudantes de tradução, que têm muita experiência na leitura e instrução formal em gramática, mas uma experiência menor de convívio com a língua, são diferentes das dificuldades na escrita de migrantes que moram em países de língua portuguesa e são fluentes em português oral. Os poucos estudos de dificuldades de migrantes russófonos na aprendizagem de português são feitos em Portugal; enquanto no Brasil, até o presente momento, foram caracterizadas somente as suas dificuldades na pronúncia de sons do português brasileiro.

\section{Corpora de aprendizes de línguas estrangeiras}

Até o presente momento, a maioria dos corpora de aprendizes de línguas estrangeiras é feita para o inglês. Uma das referências é o Corpus Internacional de Aprendizes de Inglês (ICLE, International Corpus of Learner English), que tem sido desenvolvido desde 1990 e contém 2,5 milhões de palavras, escritas por falantes de 11 línguas maternas (GRANGER et al., 2009). Ele, inclusive, contém um subcorpus chamado Br-ICLE com redações argumentativas em inglês elaboradas por brasileiros, desenvolvido com a participação de equipes de pesquisa de várias universidades brasileiras (BERBER SARDINHA, 2001; PINTO PAIVA, 2013; RECSKI, 2002). Um outro corpus, CorIsF-Inglês, contém as produções escritas e orais em inglês de brasileiros participantes do programa "Inglês sem Fronteiras" e contém dados longitudinais (DUTRA; GOMIDE, 2015). 
Para português como língua estrangeira, há alguns corpora desenvolvidos em Portugal, por exemplo: 1) Corpus de Aquisição de L2 (CAL2) da Universidade Nova de Lisboa, com 281.301 palavras, contendo tanto as produções escritas de adultos e crianças quanto as produções orais (CLUNL, 2021); 2) Corpus de Produções Escritas de Aprendentes de PL2 (PEAPL2) da Universidade de Coimbra, com 516 produções escritas contendo 119.381 palavras (CELGA-ILTEC, 2021); 3) Corpus Recolha de Dados de Aprendizagem do Português Língua Estrangeira, também desenvolvido na Universidade de Lisboa, entre 2008 e 2010, com produções de 397 informantes de 28 línguas maternas, com 70.500 palavras transcritas (LEIRIA, 2006; LEIRIA, GONÇALVES, 2021); 4) Corpus de Português Língua Estrangeira/Língua Segunda - COPLE2, desenvolvido na Universidade de Lisboa, que contém materiais escritos e orais produzidos por 483 informantes, alunos estrangeiros no processo de aprendizagem do português e candidatos a exames de certificação de proficiência, de 14 línguas maternas diferentes, com 20.996 palavras (ANTUNES et al., 2016).

No Brasil, até onde sabemos, ainda não existe um corpus de aprendizes de português como língua estrangeira de acesso aberto. A construção de um corpus desse tipo facilitaria significativamente a análise de dificuldades em português brasileiro de falantes de outras línguas maternas, incluindo a possibilidade de analisar as dificuldades em relação aos perfis linguísticos dos falantes.

\section{Material e métodos}

Os sujeitos dessa pesquisa são 12 adultos nativos de russo, um homem e 11 mulheres, residentes no Brasil. Nove sujeitos 
As principais dificuldades de imigrantes russófonos na escrita em português brasileiro: análise de redações elaboradas durante a preparação para o Celpe-Bras

nasceram na Rússia (quatro em Moscou, dois em Iaroslavl, outros em São Petersburgo, Perm e Grózni), um em Belarus, um na Ucrânia e um no Uzbequistão. A média da idade no grupo foi de 37 anos (desvio padrão de seis anos, variação dentro de 29-48 anos); o tempo médio de residência no Brasil foi de três anos (desvio padrão de dois anos, variação dentro de 0,5-7 anos). Todos tiveram pelo menos noções básicas da língua inglesa e adquiriram português sendo adultos. Fluentes em português oral no nível básico ou intermediário, todos esses sujeitos participaram de um curso preparatório para a elaboração de redações no formato exigido para o Celpe-Bras, ministrado pela autora do presente trabalho, em russo, de 21 de julho a 29 de setembro de 2018, de modo que os alunos pudessem fazer a prova do Celpe-Bras 2018-2. No momento do início do curso, três sujeitos com tempo de residência menor nunca tinham estudado português formalmente; três tinham estudado sozinhos; um com um membro da família; três com uma professora russa no Brasil; um fez curso de português de seis meses em Moscou; e um fez aulas particulares e cursos intensivos no Rio de Janeiro. O curso preparatório para o Celpe-Bras incluía 10 aulas, ministradas na modalidade on-line. Os alunos escreviam semanalmente as redações, que foram analisadas durante as aulas, sobre 12 temas no total, produzindo 92 redações; toda semana, após entregar os trabalhos, os alunos tiveram acesso à redação modelo escrita por um jornalista profissional, nativo em português, sobre o mesmo tema. Como o curso acontecia on-line, todos os trabalhos foram redigidos no computador. Como material adicional, foram recomendados o livro-texto de português para estrangeiros Bem-vindo (HARUMI DE PONCE; ANDRADE BURIM; FLORISSI, 2009), que tem foco na comunicação sem 
deixar de lado a gramática, e o livro Escrever e argumentar (KOCH; ELIAS, 2016), que contém vários exemplos de textos publicitários curtos.

O tema da primeira redação foi uma apresentação pessoal, enquanto os demais foram escolhidos a partir dos materiais das edições anteriores do Celpe-Bras, disponíveis no site da Universidade Federal do Rio Grande do Sul (SCHOFFEN, 2021): primeiro, três temas que haviam sido usados em provas orais e que integravam os chamados "Elementos Provocadores", depois oito temas de provas escritas. Os temas, fontes e números das redações produzidas estão listados na Tabela 1. Os alunos escreviam as redações conforme a sua disponibilidade, por isso nem todos escreveram sobre todos os temas, e, com o tempo, o número das redações foi diminuindo.

Tabela 1 - Os temas, fontes e números das redações produzidas no curso preparatório para o Celpe-Bras para russófonos

\begin{tabular}{|c|c|c|c|}
\hline $\begin{array}{c}\text { Numeração } \\
\text { dos temas }\end{array}$ & Tema & Fonte & $\begin{array}{c}\text { Número das } \\
\text { redaçoes } \\
\text { produzidas }\end{array}$ \\
\hline 1 & $\begin{array}{c}\text { Apresentação } \\
\text { pessoal }\end{array}$ & - & 12 \\
\hline 2 & $\begin{array}{c}\text { Ok, vocês } \\
\text { venceram! } \\
\text { As famílias } \\
\text { brasileiras têm } \\
\text { mais cães do que } \\
\text { crianças) }\end{array}$ & $\begin{array}{c}\text { Elementos } \\
\text { Provocadores } \\
2017-2, \text { Slide 1 }\end{array}$ & 9 \\
\hline 3 & $\begin{array}{c}\text { Elementos } \\
\text { Compras on-line }\end{array}$ & $\begin{array}{c}\text { Provocadores } \\
2017-2, \text { Slide 4 }\end{array}$ & 9 \\
\hline
\end{tabular}


As principais dificuldades de imigrantes russófonos na escrita em português brasileiro: análise de redações elaboradas durante a preparação para o Celpe-Bras

\begin{tabular}{|c|c|c|c|}
\hline 4 & Machismo & $\begin{array}{c}\text { Elementos } \\
\text { Provocadores } \\
\text { 2017-2, Slide } 5\end{array}$ & 10 \\
\hline 5 & $\begin{array}{l}\text { Florianópolis, } \\
\text { uma cidade } \\
\text { inteligente }\end{array}$ & $\begin{array}{c}\text { Caderno de } \\
\text { Questões 2017- } \\
\text { 2, Tarefa } 1\end{array}$ & 9 \\
\hline 6 & $\begin{array}{c}\text { Uma mulher de } \\
\text { luz }\end{array}$ & $\begin{array}{c}\text { Caderno de } \\
\text { Questões 2017- } \\
\text { 2, Tarefa } 2\end{array}$ & 10 \\
\hline 7 & Tecnoboné & $\begin{array}{c}\text { Caderno de } \\
\text { Questões 2016- } \\
\text { 1, Tarefa } 2\end{array}$ & 5 \\
\hline 8 & Cinematerna & $\begin{array}{c}\text { Caderno de } \\
\text { Questões 2014- } \\
\text { 1, Tarefa } 2\end{array}$ & 7 \\
\hline 9 & Serra da Capivara & $\begin{array}{c}\text { Caderno de } \\
\text { Questões 2017- } \\
\text { 2, Tarefa } 3\end{array}$ & 7 \\
\hline 10 & $\begin{array}{l}\text { Cadastro de } \\
\text { hortas }\end{array}$ & $\begin{array}{c}\text { Caderno de } \\
\text { Questões 2016- } \\
\text { 2, Tarefa } 3\end{array}$ & 6 \\
\hline 11 & Shopping em casa & $\begin{array}{c}\text { Caderno de } \\
\text { Questões 2016- } \\
\text { 2, Tarefa } 4\end{array}$ & 5 \\
\hline 12 & $\begin{array}{c}\text { Alunos mais ricos } \\
\text { deveriam pagar } \\
\text { pela universidade } \\
\text { pública? }\end{array}$ & $\begin{array}{c}\text { Caderno de } \\
\text { Questões 2017- } \\
\text { 2, Tarefa } 4\end{array}$ & 3 \\
\hline
\end{tabular}

Fonte: Os materiais podem ser encontrados no site da Universidade Federal do Rio Grande do Sul (SCHOFFEN, 2021).

Todos os sujeitos deram o seu consentimento para o uso das redações para esta pesquisa. A pesquisa se encaixa no projeto de pós-doutorado da autora, desenvolvido na Pontifícia Universidade Católica de São Paulo, aprovado pelo Comitê de Ética da instituição (CAAE 09079219.9.0000.5482). 


\section{Resultados e discussão}

Após a análise das 92 redações sobre 12 temas, escritas por 12 migrantes russófonos, destacamos 12 principais dificuldades desses migrantes na escrita. $\mathrm{O}$ número de ocorrências não foi analisado, e as dificuldades são apresentadas na ordem "de menor para maior", começando com ortografia e finalizando com sintaxe, como foi feito nos trabalhos de Petrova $(2011 ; 2016)$.

1) Ortografia - Como os migrantes russófonos, na maioria das vezes, adquirem o português de modo naturalístico, ouvindo e tentando interagir, a ortografia, no início de exercícios com a escrita, fica prejudicada. Nas redações do curso, encontramos formas como *"Comencamos a estudar", *“apoixanei", *"experencia", *"viagar", *“discobrir", *“demenuiu" e *“consiguiu". Uma situação especial é a escrita de "m" no final de palavras. Como em português a pronúncia de "-em" no final de palavras é realizada por uma vogal nasalizada e não por uma vogal seguida de uma consoante bilabial articulada, fácil de ser percebida, os russófonos, quando iniciantes na escrita em português, tendem a escrever "-en" em vez de "-em". Como exemplo, temos *"Ele ten vinte anos". Da mesma maneira, seguindo a pronúncia ouvida por imigrantes, "toda vez" pode ser encontrado escrito como * "toda veis". As palavras que aparentam ser termos científicos podem adquirir uma escrita parecida mais com o inglês, conforme a experiência anterior dos participantes com essa língua - por exemplo, a palavra "machismo" pode ser escrita como *"matchismo" ou *"mashismo".

2) Uso de sinais diacríticos - Como em russo não há acentos gráficos, os russófonos, mesmo acentuando as palavras 
As principais dificuldades de imigrantes russófonos na escrita em português brasileiro: análise de redações elaboradas durante a preparação para o Celpe-Bras

corretamente durante a comunicação oral, têm dificuldades em usar os acentos na escrita. Os migrantes que estão no Brasil há pouco tempo frequentemente escrevem "é” (a conjugação do verbo "ser") como “e” (a conjunção), "nós" (pronome pessoal do caso reto ou oblíquo tônico) como "nos" (pronome pessoal oblíquo átono), "está" (a conjugação do verbo "estar") como “esta” (pronome indicativo) e "dá" (conjugação do verbo “dar”) como "da" (junção da preposição "de" e o artigo definido de gênero feminino "a"). Nas redações analisadas neste trabalho, também encontramos formas como * "uteis", *“comercio"; é muito comum encontrar sem acento nenhum a palavra *"Russia", escrita da mesma maneira como se faz em inglês. $\mathrm{O}$ til, sinal de nasalização de vogais, também é frequentemente omitido por iniciantes, ainda mais que no nível de produção e, provavelmente, percepção, a nasalização de vogais também apresenta para os russófonos uma grande dificuldade (VITORIANO DE ALMEIDA et al., 2018). Os migrantes com maior experiência de escrita em língua portuguesa cometem os mesmos erros que os brasileiros, por exemplo, têm dificuldades em usar corretamente "porque", "por que", "por quê" e "porquêe".

3) Uso de artigos - As dificuldades no uso de artigos em português por russófonos já foram amplamente relatadas nos trabalhos de Petrova (2011; 2016) e Baldé (2011). Quando os falantes de uma língua que não possui artigos aprendem uma outra língua na qual os artigos são usados, essas dificuldades são esperadas e amplamente pesquisadas, usando os protocolos específicos (IONIN; KO; WEXLER, 2004). Nas redações analisadas neste trabalho, os russófonos frequentemente usaram o nome do país "Brasil" sem artigo, e também usaram formas como * sabendo de urgência", *"Nós temos filha" ou *،obteve o amplo alcance". 
4) Concordância em gênero - Nas redações analisadas neste trabalho, encontramos formas como *“árvores fantástico", *"muitos pequenos casas", *"muitos pessoas", *“fatores positivas e negativas", *“muito gente", *"os religiões", *“sugestões do população", *"soluções tecnológicos", *"possibilidades novos", *"atividades do Polícia Militar", *“acesso ao informação", *“o projeto é voltada", "foram utilizado a técnica", *“alimentação orgânico". É muito comum a forma *"pelo internet”, já que, em russo, a palavra "internet" pronuncia-se de uma maneira muito parecida e é do gênero masculino. Da mesma maneira, os russófonos frequentemente escrevem *"uma tema", *uuma problema", já que essas palavras em russo têm pronúncia parecida e são do gênero feminino. Uma outra dificuldade é relacionada aos nomes de cidades: em russo, as cidades sempre têm gênero conforme a terminação do nome próprio, por exemplo, СанктПетербург (São Petersburgo) termina com uma consoante e assim é do gênero masculino; Москва (Moscou) em russo termina com a vogal "-a" e assim é do gênero feminino. Além disso, a palavra "cidade" em russo (2opod) também é do gênero masculino, assim, é muito comum encontrar nas redações a cidade de São Paulo tratada como sendo de gênero masculino: *“São Paulo foi escolhido...”.

5) Uso do verbo "ser" - Como em russo o verbo "ser" no presente é omitido, os migrantes russófonos, no começo, sentem dificuldade de se lembrar de empregá-lo, assim, aparecem frases como *"Meu nome Maria", *"Meu marido brasileiro. Eu tenho duas crianças" ou *“Eu de Cazaquistão". 
As principais dificuldades de imigrantes russófonos na escrita em português brasileiro: análise de redações elaboradas durante a preparação para o Celpe-Bras

6) Uso de verbos "ter/haver" - Como na fala coloquial os falantes nativos de português brasileiro frequentemente usam o verbo "ter" no sentido de "haver" e os migrantes ouvem essa construção, eles a introduzem na escrita em estilo formal, como, por exemplo, em *“Em São Paulo tem 25 hortas”.

7) Conjugação de verbos - Quando iniciantes em português, os migrantes russófonos podem conjugar os verbos por escrito de maneira agramatical, por exemplo, *"Eu chegou", *“Eu achou", *"Eu gosta", *“Os voluntários estamos muito preocupados" ou * "Eu foi convidada". A escrita da terminação "-o", na conjugação dos verbos, no presente, na primeira pessoa no singular, apresenta uma dificuldade adicional, porque, em russo, /o/ átono frequentemente se pronuncia como [ $\Lambda$ ] (SMIRNOVA HENRIQUES et al., 2019), assim, os russófonos ajustam a escrita à sua pronúncia.

8) Uso de tempos verbais - Como em russo o sistema verbal é totalmente diferente do português e os aspectos de perfectivo/ imperfectivo são introduzidos através do uso de verbos diferentes e não de tempos verbais (SILVA, 2009), os russófonos começam a ter dificuldades no uso de tempos verbais assim que descobrem a existência em português do contraste entre pretérito perfeito e pretérito imperfeito. Nas nossas redações, os russófonos apresentavam dificuldades na escolha entre "Antes eu morava" e "Antes eu morei", ou entre "Trabalhava no banco durante 27 anos" e "Trabalhei no banco durante 27 anos".

9) Uso do modo subjuntivo - Em russo, os verbos no modo subjuntivo não têm indicadores morfológicos de tempo, eles adquirem a mesma terminação que se usa para a conjugação 
no pretérito do modo indicativo. Dessa maneira, o uso de tempos verbais no modo subjuntivo apresenta uma dificuldade significativa, mesmo para os russófonos com um bom domínio de português. Nas nossas redações, encontramos formas como * "Espero que em breve esse problema desapareceu", mas o uso foi mínimo. Como o curso preparatório começou somente três meses antes da prova do Celpe-Bras 2018-2, os alunos foram orientados a identificar e evitar na escrita as construções que envolvessem o uso do subjuntivo.

10) Regência de verbos e uso de preposições - Os migrantes russófonos frequentemente encontram dificuldades com regência verbal e uso de preposições na escrita: na aquisição "de ouvido", é difícil identificar esses elementos. Nas redações desse curso, encontramos frases como *"Ela estudou por engenharia e economia", *“Eu gosto flores”, *“Eu sonhei por isso". Além disso, eles trazem para a escrita formal formas coloquiais, como, por exemplo, "ir no supermercado".

11) Ordem de palavras - Em russo, a ordem estilisticamente neutra é um determinante seguido por determinado, assim, os adjetivos precedem substantivos e os advérbios precedem verbos. Os migrantes russófonos frequentemente aplicam esse tipo de construção em português, dessa maneira, escrevendo frases como *"Eu muito gosto".

12) Diferença entre "que" e "o que" - Além de, em russo, não existirem artigos, o que frequentemente leva ao seu uso incorreto em português, os termos "que" e "o que" correspondem, em russo, a uma mesma palavra чmo. Isso leva ao uso de construções como *“Eu acho o que...". 
As principais dificuldades de imigrantes russófonos na escrita em português brasileiro: análise de redações elaboradas durante a preparação para o Celpe-Bras

Depois do curso, oito sujeitos participaram da sessão do Celpe-Bras 2018-2, três participaram em 2019 e somente um não se inscreveu. Quatro sujeitos obtiveram o nível intermediário superior, três o intermediário, um o avançado e um o avançado superior. Um não passou em duas tentativas e também não fez qualquer outro tipo de avaliação; um não passou no Celpe-Bras, mas, mais tarde, prestou Enem e obteve as notas suficientes para ingressar em uma faculdade privada.

\section{Considerações finais}

No presente trabalho, descrevemos as principais dificuldades de migrantes russófonos, residentes no Brasil, na escrita das redações no formato do Celpe-Bras. Nos trabalhos anteriores, foi relatado que mais da metade dos migrantes russófonos aprende português no Brasil de maneira autônoma, depois da sua chegada ao país (SMIRNOVA HENRIQUES et al., 2019; 2020); entre os sujeitos participantes deste estudo, sete das 12 pessoas, mesmo três meses antes da sessão da prova do Celpe-Bras pretendida, ainda não tinham experiência de instrução formal em português. Como a maioria dos imigrantes russófonos que vêm para o Brasil possui educação superior (SMIRNOVA HENRIQUES et al., 2020), eles têm facilidade de organizar bem a estrutura do texto, e as dificuldades se encontram no nível mais básico, causadas pelo pouco contato com a língua portuguesa escrita e a falta de instrução formal em português.

Muitas das dificuldades observadas nas redações dos migrantes russófonos, no presente trabalho, coincidem com as dificuldades de estudantes de tradução da MGIMO, descritas por Petrova $(2011 ; 2016)$; no entanto, os migrantes russófonos, 
diferentemente dos alunos de tradução que estudam no ambiente acadêmico, estão em imersão diária na língua portuguesa, e a sua competência oral se desenvolve muito antes da escrita, assim como observado por Silva (2009), em Portugal. Observando os exemplos de dificuldades dos migrantes na concordância de gênero, como * "fatores positivas e negativas", *"sugestões do população", *"soluções tecnológicos", *“atividades do Polícia Militar", *“acesso ao informação" ou *“alimentação orgânico", percebemos que eles possuem um bom vocabulário, ou a capacidade de trabalhar esse vocabulário a partir dos textos apresentados, e, ao mesmo tempo, não possuem instrução sobre como funcionam os gêneros em português. Os erros de ortografia e as dificuldades no uso de sinais diacríticos também são específicos de migrantes: os alunos de tradução aprendem isso através da instrução formal.

Enquanto, em Portugal, já existem trabalhos que caracterizam algumas dificuldades de migrantes russófonos na aprendizagem de português, como o uso de artigos (BALDÉ, 2011) e a compreensão de aspectos verbais (SILVA, 2009), no Brasil, os estudos em relação a esses migrantes, até este momento, foram limitados às dificuldades da pronúncia (VITORIANO DE ALMEIDA et al., 2018; SMIRNOVA HENRIQUES et al., 2019; 2020; SMIRNOVA HENRIQUES; BARROS; MADUREIRA, 2020). Um estudo mais aprofundado das dificuldades apresentadas é necessário para orientar os professores na preparação de cursos de português como língua estrangeira e na elaboração de materiais didáticos para falantes de russo e outras línguas eslavas que possuem a estrutura parecida: para os migrantes, a questão de escrever corretamente, seguindo o estilo formal, não é uma questão de medo de preconceitos linguísticos, mas de ter ou não a possibilidade 
As principais dificuldades de imigrantes russófonos na escrita em português brasileiro: análise de redações elaboradas durante a preparação para o Celpe-Bras

de adquirir a cidadania brasileira e acompanhar melhor a sua família no seu ritmo de vida (ANUNCIAÇÃO; CAMARGO, 2019; SMIRNOVA HENRIQUES; RUSEISHVILI, 2019).

No Brasil, há muitos pesquisadores que trabalham com a análise de textos produzidos por estrangeiros, inclusive com o foco nas tarefas aplicadas no Celpe-Bras (DAMAZO, 2012; GAO, 2012; ORRA, 2013; SALES, 2014). No entanto, até onde sabemos, não existe um corpus de acesso aberto no qual as redações produzidas por aprendizes de português brasileiro poderiam ser depositadas. No nosso trabalho, juntamos 92 redações digitadas por migrantes russófonos no computador. Assim que os esforços da comunidade científica que estuda português brasileiro como língua estrangeira se concretizarem na criação de um corpus correspondente, daremos prosseguimento com a disponibilização das redações analisadas nesta pesquisa. Normalmente, nos cursos presenciais, os alunos escrevem textos à mão, e isso dificulta a digitalização do conteúdo; no entanto, na época do ensino a distância, estimulado devido à pandemia de Covid-19, é possível que o número de redações digitadas no computador tenha aumentado. Dessa maneira, é importante que a questão de criação de corpus de aprendizes de português brasileiro como língua estrangeira seja discutida abertamente: é possível que vários professores já disponham de material digital no formato adequado e só esteja faltando um impulso organizacional.

\section{Agradecimentos:}

Dra. Smirnova Henriques é bolsista de PNPD/Capes (Programa Nacional de Pós-Doutorado da Coordenação de Aperfeiçoamento de Pessoal de Nível Superior). O jornalista Dr. Fernando Kuhn contribuiu enormemente na organização dos 
materiais para o curso preparatório para o Celpe-Bras para os russófonos, na correção das redações dos migrantes e escrita das redações-modelo. Nossos agradecimentos à Profa. Dra. Sandra Madureira (PUC-SP) e ao jornalista Dr. Fernando Kuhn pela revisão do manuscrito.

\section{Referências}

ACNUR. Alto Comissariado das Nações Unidas para Refugiados. Perfil socioeconômico dos refugiados no Brasil. 2019. Disponível em: <https://www.acnur.org/portugues/wp-content/ uploads/2019/07/Pesquisa-Perfil-Socioecon\%C3\%B4micoRefugiados-ACNUR.pdf $>$. Acesso em: 19 out. 2020.

ADAM, Andreia Ros Segundo; FERNANDES MASSUCI, Camila; FURTOSO, Viviane Bagio. Formação de professores de PFOL na graduação: relato de experiência. In: FURTOSO, Viviane Bagio (org.). Formação de professores de português para falantes de outras línguas. Londrina: Eduel, 2009. p. 6576.

AMADO, Rosane de Sá. O ensino de português como língua de acolhimento para refugiados. Revista da Sociedade Internacional Português Língua Estrangeira-SIPLE, [s. l.], v. 4, n. 2, p. 1-6, 2013.

ANTUNES, Sandra et al. Apresentação do corpus de Português Língua Estrangeira/Língua Segunda - COPLE2. Revista da Associação Portuguesa de Linguística, [s. l.], n. 1, p. 1-11, 2016. Disponível em: <http://ojs.letras.up.pt/index.php/APL/ article/view/1586>. Acesso em: 13 mar. 2021.

ANUNCIAÇÃO, Renata; CAMARGO, Helena. O exame do Celpe-Bras como política de gatekeeping para naturalização no Brasil. Muiraquitã - Revista de Letras e Humanidades, [s. l.], v. 7, n. 2, p. 10-22, 2019. 
As principais dificuldades de imigrantes russófonos na escrita em português brasileiro: análise de redações elaboradas durante a preparação para o Celpe-Bras

AREFIEV, Aleksandr. Sotrudnichestvo Rossii i Portugalii v oblasti obrazovaniya i vzaimnoe izuchenie iazykov [Cooperation between Russia and Portugal in the education field and mutual learning of languages]. In: NIKUNLASSI, Ahti; PROTASSOVA, Ekaterina. (Ed.). Slavica Helsingiensia 52. Russian Linguage in the Multilingual World. Helsinki: University of Helsinki, 2019. p. 123-133.

BALDÉ, Nailia Rafikovna. A aquisição do artigo em português L2 por falantes de L1 russo. 2011. 111 f. Dissertação (Mestrado em Linguística) - Faculdade de Letras, Universidade de Lisboa, Lisboa, Portugal. Disponível em: <https://repositorio.ul.pt/ bitstream/10451/4137/1/ulf1096186_tm.pdf $>$. Acesso em: 13 mar. 2021.

BERBER SARDINHA, Antonio Paulo. O corpus de aprendiz Br-ICLE. Intercâmbio, [s. l.], v. 10, p. 227-239, 2001.

BRASIL. Portaria Interministerial no 11, de 3 de maio de 2018. Dispõe sobre os procedimentos para solicitação de naturalização, de igualdade de direitos, de perda, de reaquisição de nacionalidade brasileira e de revogação da decisão de perda da nacionalidade brasileira e dá outras providências. Diário Oficial da União, Brasília, DF, 4 maio 2018. Seção 1, ed. 85, p. 46.

CELGA-ILTEC. Centro de Estudos de Linguística Geral e Aplicada da Universidade de Coimbra. Corpus de Produções Escritas de Aprendentes de PL2 (PEAPL2). 2021. Disponível em: $\quad<$ http://teitok2.iltec.pt/peapl2/index.php?action=home $>$. Acesso em: 14 mar. 2021.

CLUNL. Centro Linguístico da Universidade Nova de Lisboa. CAL2 - Corpus de Aquisição de L2. 2021. Disponível em: $<$ https://clunl.fcsh.unl.pt/recursos-em-linha/corpora/corpus-deaquisicao-de-12/>. Acesso em: 14 mar. 2021.

DAMAZO, Liliane Oliveira. A modalização na produção de textos em português como língua estrangeira. 2012. 220 f. Dissertação (Mestrado em Estudos de Linguagens) - 
Centro Federal de Educação Tecnológica de Minas Gerais, Belo Horizonte. Disponível em: <http://www.ufrgs.br/ acervocelpebras/arquivos/textos-publicados/damazo-lilianeoliveira $>$. Acesso em:13 mar. 2021.

DUTRA, Deise Prina; GOMIDE, Andressa Rodrigues. Compilation of a University Learner Corpus. BELT, [s. l.], v. 6, p. s21-s33, 2015. Disponível em: <https://doi.org/10.15448/21783640.2015.s.21311>. Acesso em: 13 mar. 2021.

FARNEDA, Eliete Sampaio. Português língua de acolhimento cursos de extensão e capacitação para professores de português língua materna: abordagens e práticas. In: MAIA, Francisca Paula Soares; MENDES, Regina Maria Gonçalves. (Ed.). Ensino e aprendizagem de línguas adicionais em foco. Roosevelt, NJ: Boavista Press, 2019. p. 53-64.

GAO, Jingran. Práticas de avaliação de textos em português produzidos por falantes de chinês. 2012. 179 f. Dissertação (Mestrado em Letras) - Instituto de Letras, Universidade Federal do Rio Grande do Sul, Porto Alegre. Disponível em: <https:// lume.ufrgs.br/handle/10183/67440>. Acesso em: 13 mar. 2021.

GRANGER, Sylviane et al. (Ed.). International corpus of learner English. Version 2. Louvain-la-Neuve: Presses Universitaires de Louvain, 2009.

HARUMI DE PONCE, Maria; ANDRADE BURIM, Sílvia; FLORISSI, Susanna. Bem-vindo! A língua portuguesa no mundo da comunicação. 8. ed. São Paulo: Special Book Services Livraria, 2009.

IONIN, Tania; KO, Heejeong; WEXLER, Kenneth. Article semantics in L2 acquisition: the role of specificity. Language Acquisition, [s. l.], v. 12, n. 1, p. 3-69, 2004.

$\mathrm{KOCH}$, Ingedore Vilaça; ELIAS, Vanda Maria. Escrever e argumentar. São Paulo: Editora Contexto, 2016. 
As principais dificuldades de imigrantes russófonos na escrita em português brasileiro: análise de redações elaboradas durante a preparação para o Celpe-Bras

LEIRIA, Isabel. Léxico - aquisição e ensino do Português Europeu língua não materna. Lisboa: Fundação Calouste Gulbenkian; Fundação para a Ciência e a Tecnologia, 2006. Disponível em: <https://repositorio.ul.pt/handle/10451/39233>. Acesso em: 13 mar. 2021.

LEIRIA, Isabel; GONÇALVES, Rita. Recolha de dados de PLE. 2021. Disponível em: <http://www.clul.ulisboa.pt/recurso/ recolha-de-dados-de-ple>. Acesso em: 14 mar. 2021.

ORRA, Samira Ahmad. Tempo, aspecto e modo verbais e o gênero textual carta do leitor: análise de tarefas do Celpe-Bras. 2013. 95 f. Dissertação (Mestrado em Letras) - Faculdade de Filosofia, Letras e Ciências Humanas, Universidade de São Paulo. Disponível em: <https://teses.usp.br/teses/disponiveis/8/8142/ tde-26022014-151030/pt-br.php>. Acesso em: 13 mar. 2021.

PANARIN, Serguei. Russkojazychnye u vneshnih granits Rossii: vyzovy i otvety (na primere Kazahstana) [Russophones near to the external borders of Russia: challenges and answers (on the exemple of Kazakhstan)]. Diaspory, [s. l.], n. 2-3, p. 136168, 1999. Disponível em: <http://www.archipelag.ru/ru_mir/ rm-diaspor/russ/russian-speaking/>. Acesso em: 13 mar. 2021. PÉRET DELL'ISOLA, Regina Lúcia. Exame de proficiência Celpe - Bras em foco. Campinas: Pontes Editores, 2014.

PETROVA, Galina Viktorovna. O ensino de Português - Língua Estrangeira no contexto tipologicamente distinto. Revista electrónica da Associação de Professores de Português, [ $s$. l.], n. 2, p. 1-8, 2011.

PETROVA, Galina Viktorovna. Oshibki uchenikov kak zerkalo strukturnyh razlichij mezhdu portugal"skim i russkim jazykami [Student mistakes as a mirror of structural differences between Portuguese and Russian]. Iberoamerikanskie tetradi, [s. l.], n. 1, p. 123-127, 2016. Disponível em: <https://doi. org/10.46272/2409-3416-2016-1-123-137>. Acesso em: $13 \mathrm{de}$ mar. de 2021 . 
PETROVA, Galina Viktorovna. Conceitos do tempo e do espaço em russo e em português: diferenças e dificuldades na aprendizagem. Studia Iberystyczne, $[s . l$.$] , v. 18, p.$ 467-478, 2019. Disponível em: <https://doi.org/10.12797/ SI.18.2019.18.32>. Acesso em: 13 mar. 2021.

PINTO PAIVA, Paula Tavares. Instrumentos e atividades realizadas para a coleta de um corpus de aprendizes em língua inglesa para integrar o Br-ICLE (Brazilian Portuguese Subcorpus of ICLE). Estudos Linguísticos, [s. l.], v. 42, n. 1, p. 312-322, 2013. Disponível em: <https://repositorio.unesp.br/ handle/11449/122351>. Acesso em: 13 mar. 2021.

RECSKI, Leonardo Juliano. Computer-assisted error analysis: a study of prepositional errors in the Brazilian subcomponent of the international corpus of learner english (Br-ICLE). 2002. $127 \mathrm{f}$. Dissertação (Mestrado em Letras) - Programa de Pós-Graduação em Letras/Inglês e Literatura Correspondente, Universidade Federal de Santa Catarina, Florianópolis. Disponível em: $<$ https://repositorio.ufsc.br/xmlui/handle/123456789/83383>. Acesso em: 13 mar. 2021.

SALES, Hellen Margareth Pompeu de. A produção escrita em turmas heterogêneas de português língua estrangeira: das tarefas ao exame Celpe-Bras. 2014. 205 f. Dissertação (Mestrado em Letras) - Instituto de Letras e Comunicação, Universidade Federal do Pará, Belém. Disponível em: $<\mathrm{http}: / /$ repositorio.ufpa. br/jspui/handle/2011/5844>. Acesso em: 10 mar. 2021.

SCHOFFEN, Juliana Roquele. Acervo de provas e documentos públicos do Celpe-Bras. 2021. Disponível em: $<$ http://www. ufrgs.br/acervocelpebras>. Acesso em: 7 mar. 2021.

SILVA, Catarina Pereira da. Oposições aspectuais em português como língua segunda: o caso dos falantes de russo em contexto de imersão. 2009. 106 f. Dissertação (Mestrado em Linguística, Português Língua Estrangeira e Língua Segunda) - Faculdade de Letras da Universidade de Coimbra, Coimbra, 
As principais dificuldades de imigrantes russófonos na escrita em português brasileiro: análise de redações elaboradas durante a preparação para o Celpe-Bras

Portugal. Disponível em: <https://estudogeral.sib.uc.pt/ handle/10316/13482>. Acesso em: 13 mar. 2021.

SISMIGRA. Sistema de Registro Nacional Migratório. Departamento da Polícia Federal - Ministério da Justiça e Segurança Pública do Brasil/OBMigra. Tabulações: Banco Interativo do Observatório das Migrações em São Paulo NEPOUNICAMP - CNPq/MPT. Imigrantes internacionais registrados (Registro Nacional de Estrangeiro - RNE/ Registro Nacional Migratório - RNM. 2020. Disponível em: $<$ https://www.nepo.unicamp.br/observatorio/bancointerativo/ numeros-imigracao-internacional/sincre-sismigra/>. Acesso em: 13 out. 2020 .

SMIRNOVA HENRIQUES, Anna et al. Russian immigrants in Brazil: to understand, to be understood. Cadernos de Linguística, [s. l.], v. 1, n. 2, p. 1-18, 2020. Disponível em: $<$ https://doi.org/10.25189/2675-4916.2020.v1.n2.id210 $>$. Acesso em: 13 mar. 2021.

SMIRNOVA HENRIQUES, Anna et al. The perception of Brazilian Portuguese open and close mid vowels by native Russian speakers. JoSS, [s. l.], v. 8, n. 2, p. 59-84, 2019. Disponível em: <http://revistas.iel.unicamp.br/ojs_joss/index. php/journalofspeechsciences/article/view/183/162>. Acesso em: 13 mar. 2021.

SMIRNOVA HENRIQUES, Anna; BARROS, Thaiza; MADUREIRA, Sandra. Proficiência oral em Português Brasileiro: cenário, contextos de avaliação e de instrução e questionamentos. Revista da ABRALIN, [s. l.], v. 19, n. 3, p. 775-798, 2020. Disponível em: <https://doi.org/10.25189/ rabralin.v19i3.1755>. Acesso em: 13 mar. 2021.

SMIRNOVA HENRIQUES, Anna; RUSEISHVILI, Svetlana. Migrantes russófonos no Brasil no século XXI: perfis demográficos, caminhos de inserção e projetos migratórios. Ponto-e-Vírgula, [s. l.], n. 25, p. 83-96, 2019. Disponível em: $<$ https://doi.org/10.23925/1982-4807.2019i25p83-96 $>$. Acesso em: 13 mar. 2021. 
STSEPANIUK, Anzhalika. Método de ensino de português para falantes de russo: proposta de materiais didáticos bilíngues. 2014. 86 f. Dissertação (Mestrado em Ensino do Português como Língua Segunda e Estrangeira) - Faculdade de Ciências Socias e Humanas, Universidade Nova de Lisboa, Lisboa, Portugal. Disponível em: <https://run.unl.pt/handle/10362/14310>. Acesso em: 13 mar. 2021.

TRAVINA, Iuliia. O ensino do Português Língua Estrangeira para o público jovem: uma experiência de introdução do curso de PLE num campo de férias na Rússia. 2019. $152 \mathrm{f}$. Dissertação (Mestrado em Português Língua Estrangeira/Língua Segunda) - Faculdade de Letras, Universidade de Lisboa, Lisboa, Portugal. Disponível em: <https://repositorio.ul.pt/ handle/10451/40804?locale=en>. Acesso em: 10 mar. 2021.

VITORIANO DE ALMEIDA, Katerine et al. Produção oral de falantes russos que aprendem português brasileiro. In: CONGRESSO BRASILEIRO DE FONOAUDIOLOGIA, 26., 2018, Curitiba. Anais [...]. Curitiba: Universidade Tuiuti do Paraná, 2018. Disponível em: <https://www.sbfa.org.br/portal/ anais2018/trabalhos_select.php?tt $=$ Busca\&id_artigo $=10365>$. Acesso em: 10 jan. 2021.

VOROBYEVA, Olga; ALESHKOVSKI, Ivan; GREBENYUK, Aleksandr. Russian emigration at the turn of the 21st century. Filosofija Sociologija, [s. l.], v. 29, n. 2, p. 107-118, 2018. Disponível em: <https://doi.org/10.6001/fil-soc.v29i2.3706>. Acesso em: 13 mar. 2021.

ZHOU, Xie; KOLODA, Svetlana. K voprosu ob ispol'zovanii termina "russkojazychnyecrusskogovorjashhie) strany" v gumanitarnyh issledovanijah [On the use of the term «Russianspeaking countries» in the humanitarian studies]. Mir russkogovorjashhih stran. Regionovedenie, [s. l.], n. 1, p. 3642, 2019. 